\title{
GERNIKAKO ARBOLA, UN HIMNO HUÉRFANO
}

\section{GERNIKAKO ARBOLA, AN ORPHANED ANTHEM}

\author{
Xabier Zabaltza \\ Universidad del País Vasco/Euskal Herriko Unibertsitatea (España) \\ ORCID: orcid.org/0000-0001-8743-3084
}

Recibido el 13-11-2015 y aceptado el 5-10-2016

Resumen: La primera interpretación documentada del Gernikako Arbola tuvo lugar en Madrid en 1853. Considerado ya en vida de su autor como himno nacional vasco, no es, en cambio, un himno nacionalista. Es un canto a la solidaridad de Álava, Guipúzcoa, Navarra y Vizcaya, pero sin cuestionar la unidad de España. Ha contado con una difusión extraordinaria también en las provincias vasco-francesas de Baja Navarra, Labort y Sola, así como en las colectividades vascas del exterior. Por razones opuestas, ha sido rechazado por sectores del navarrismo y del nacionalismo vasco. El universalismo y el pacifismo que rezuma el Gernikako Arbola lo diferencian de otros himnos patrióticos.

Palabras clave: José María Iparraguirre (1820-1881). Gernika. Fuerismo. Nacionalismo vasco. Navarrismo.

\begin{abstract}
The first documented performance of Gernikako Arbola took place in Madrid in 1853. Considered in the lifetime of its author a national anthem, it is not, however, a nationalist anthem. It is a hymn to the solidarity of Alava, Biscay, Guipuzcoa and Upper Navarre, but without questioning the unity of Spain. It has also been extraordinarily popular in the French Basque provinces of Labourd, Lower Navarre and Soule, as well as in the Basque communities abroad. For opposite reasons, it has been rejected by sectors of Navarresism and Basque nationalism. The universalism and the pacifism that Gernikako Arbola oozes distinguish it from other patriotic anthems.
\end{abstract}

Key words: José María Iparraguirre (1820-1881). Gernika. «Fuerism». Basque nationalism. Navarresism. 


\section{EI Roble de Gernika}

Para entender la trascendencia histórica del Gernikako Arbola, lo primero que hay que saber es que el País Vasco, como entidad administrativa civil, es una creación del siglo Xx. Salvadas dos breves coyunturas bélicas, durante la Guerra de la Independencia (1810-1813) y la última Guerra Civil (1936-1937), hasta 1979 no existió una región autónoma que reuniera a Álava (Araba, en vascuence), Guipúzcoa (Gipuzkoa) y Vizcaya (Bizkaia). Y después de esa fecha, Navarra (Nafarroa) y, por supuesto, las provincias vasco-francesas de Baja Navarra (Baxenabarre), Labort (Lapurdi) y Sola (Zuberoa), siguieron sin ser incluidas en ella. La denominada Comunidad Autónoma del País Vasco (Euskadi) no engloba, ni ha englobado nunca, a todos los territorios con población vasca (Euskal Herria) ${ }^{1}$. Como se verá a continuación, hasta bien entrado el siglo XIX, el Roble de Gernika, a cuya sombra tenían lugar las Juntas Generales del Señorío de Vizcaya, solo evocaba alguna significación a los vizcainos. Su conversión en símbolo de toda Vasconia es un aspecto más del proceso de nacionalización vasca, al que no fue ajeno el genio de José María Iparraguirre.

El roble era un árbol sagrado para celtas, romanos y otros pueblos indoeuropeos. Representaba al dios Júpiter y el poder del rayo y para el imaginario popular ocupaba en el Reino Vegetal un lugar análogo al del león en el Reino Animal y al del oro en el Reino Mineral ${ }^{2}$. Caro Baroja ha documentado casos de dendrolatría en todo el norte de la Península Ibérica, incluidos los territorios vascos occidentales ${ }^{3}$. Uno de los dioses de los antiguos aquitanos, que hablaban una lengua parecida al vascuence, era Arixo, en cuyo nombre se reconoce el étimo ( $h$ aritz, «roble» y también «árbol» en general ${ }^{4}$. Incluso hoy en día el roble es el árbol nacional de múltiples países, entre ellos, Inglaterra, Estados Unidos, Estonia, Alemania y Moldavia ${ }^{5}$.

1 Euskal Herria es un término popular para referirse a los territorios en los que se habla vascuence. Se utiliza en la literatura vasca por lo menos desde 1567 . Su calco castellano «País Vasco» se documenta desde 1818, cuando la lengua vasca abarcaba dos tercios de Navarra. Euzkadi o Euskadi es, en cambio, un neologismo de clara connotación política, acuñado por Sabino Arana en 1896. Zabaltza, 2005, pp. 23-33. En este artículo se utiliza el cultismo «Vasconia» como equivalente de Euskal Herria en castellano.

2 Frazer, 1951 [1890], especialmente pp. 793-795; Tillyard, 2011 [1959], p. 30.

3 Caro Baroja, 1989 [1974], p. 339.

${ }^{4}$ Barandiarán, 1972; Caro Baroja, 1989 [1974], p. 312; Agud y Tovar, 1990.

5 De Pablo, 2012, p. 648. 
Durante la Baja Edad Media y la Edad Moderna existieron robles junteros en gran parte de la actual Vasconia. En Álava se documenta uno, en Barajuen (Aramaio), colindante con Vizcaya. También en Álava, en Luiaondo (Ayala), se hallaba el árbol «gafo» o «malato», que marcaba el límite del Señorío de Vizcaya. Sin embargo, la Cofradía de Arriaga, la máxima autoridad del territorio alavés hasta el siglo XIV, no se reunía bajo un roble, sino en campo abierto. En cambio, en Labort, el Bilçar sí que se juntaba bajo un roble, en Haitze (Ustaritz). En Guipúzcoa, por su parte, coexistían 18 villas junteras, lo que impidió la mitificación de un lugar equivalente a Gernika. Las asambleas vecinales de los pueblos de la Provincia, más que bajo un roble concreto, solían realizarse en bosques de robles, por ejemplo, en el de Enekosaustegi, en Zestoa (que era villa juntera), y en el de Elizalde, en Usurbil (que no lo era). En Vizcaya, además del de Gernika, el más honorable de todos los robles vascos, son conocidos los de las juntas privativas de las Encartaciones (en Avellaneda), del Duranguesado (en Gerediaga) y del Valle de Orozko (en Larrazabal), las tres entidades de la Vizcaya no nuclear. En la Vizcaya nuclear funcionaron como robles junteros los de Aretxabalaga (en la merindad de Uribe) y Sagastiguren (en la merindad de Markina). El de Aretxabalaga, que podría ser idéntico al de Idoibaltzaga, donde se reunía la Junta de Merindades, y al de Gerekiz, que Chaho atribuye erróneamente a los várdulos, formaba parte de la ruta que seguían los reyes de Castilla para jurar los fueros vizcainos. Salvo error por mi parte, los tres territorios vascos orientales (Navarra, Baja Navarra y Sola), así como las merindades vizcainas de Arratia, Bedia y Zornotza, que hasta el siglo XV estuvieron unidas, carecían de roble juntero ${ }^{6}$.

Entre las primeras documentadas, en 1308, y las últimas, en 1877, las Juntas Generales de Vizcaya, que ya en 1342 se celebraron en el lugar de Gernika, en la anteiglesia de Lumo de la Merindad de Busturia (antes incluso de la fundación de la villa en 1366), fueron cobrando progresivamente importancia en el complejo entramado institucional del Señorío ${ }^{7}$. Desde Alfonso XI (1334) a Felipe V (1702) los reyes de Castilla jura-

${ }^{6}$ Chaho, 1845; Olascoaga, 1909; Caro Baroja, 1989 [1974], pp. 353-391; Estornés Zubizarreta, 1976; García de Cortázar et al., 1985, IV, pp. 22-25; Luengo Teixidor y Delgado Cendagortagalarza, 2006; Madariaga Orbea, 2006; García Quintela y Delpech, 2013.

7 Monreal Cía, 1974, pp. 327-470; Guezala, 1992, pp. 41-64. 
ron los fueros vizcainos en Gernika (a menudo por medio de un representante), pero esa costumbre quedó después relegada al olvido, hasta que fue recuperada por el pretendiente carlista Carlos María Isidro «Carlos V» $(1834)^{8}$. A partir del siglo XVII, si no antes, las asambleas vizcainas, concebidas como guardianas de las libertades locales frente al absolutismo regio, fueron idealizadas no solo en Vizcaya, sino también fuera de ella. Al Árbol de Gernika cantaron, entre otros ${ }^{9}$, el castellano Tirso de Molina (1571-1648)

El árbol de Garnica ha conservado la antigüedad que ilustra a sus señores, sin que tiranos le hayan deshojado, ni haga sombra a confesos ni a traidores. En su tronco, no en silla real sentado, nobles, puesto que pobres electores, tan sólo un señor juran, cuyas leyes libres conservan de tiranos reyes ${ }^{10}$

y el inglés William Wordsworth (1770-1850)

OAK of Guernica! Tree of holier power Than that which in Dodona did enshrine (So faith too fondly deemed) a voice divine Heard from the depths of its aerial bowerHow canst thou flourish at this blighting hour?

What hope, what joy can sunshine bring to thee, Or the soft breezes from the Atlantic sea, The dews of morn, or April's tender shower? Stroke merciful and welcome would that be Which should extend thy branches on the ground, If never more within their shady round

${ }^{8}$ Elías de Tejada, 1963, pp. 19, 51 y 68; Caro Baroja, 1989 [1974], pp. 360-363 y 389 , nota 129; Laborda, 2012, pp. 122, 152 y 155. Después de 1834, los fueros vizcainos fueron jurados por el pretendiente carlista Carlos María de Borbón y Austria-Este «Carlos VII» (1875) y, en dos ocasiones, por el regente Javier de Borbón-Parma (1937 y 1950).

9 A pesar de mis esfuerzos, no he conseguido localizar la frase atribuida a Rousseau («Guernica es el pueblo más feliz del mundo. Sus asuntos los gobierna una junta de campesinos que se reúne bajo un roble, y siempre toman las decisiones más justas»), así que la considero apócrifa mientras no se demuestre lo contrario.

${ }_{10}$ Molina, 2004 [1634], p. 11. 
Those lofty-minded Lawgivers shall meet, Peasant and lord, in their appointed seat, Guardians of Biscay's ancient liberty ${ }^{11}$.

Pero lo que verdaderamente contribuyó al renombre del Roble de Gernika fuera de Vasconia fue un acontecimiento que tuvo lugar a casi mil kilómetros de distancia. Los revolucionarios de 1789 convirtieron a los árboles en emblemas de la libertad y plantaron miles de ellos a lo largo del territorio rescatado del despotismo ${ }^{12}$. Cuando, con motivo de la Guerra de la Convención, los franceses llegaron a Gernika (1795), debieron de sorprenderse al comprobar que los vizcainos ya contaban con su propio Árbol de la Libertad ${ }^{13}$. Aunque no está claro, parece que remplazaron el viejo roble por uno más joven ${ }^{14}$. Desde entonces, «Gernika» tuvo un significado biunívoco. Por un lado, siguió siendo el símbolo de los antiguos fueros. Por otro lado, se identificó también con las nuevas libertades que proclamaba la Revolución.

Un escritor vasco-francés ya citado, el suletino Augustin Chaho (1811-1858), que era revolucionario en Francia y carlista en España, unió ambas tradiciones y, por primera vez, confirió al Roble de Gernika un simbolismo nacional, panvasco. Gernika ya no pertenecía solo a Vizcaya, sino al conjunto de Vasconia. Más aún. Chaho, que se consideraba el profeta de la nueva religión nacional y que, como todos los profetas, escribía de una manera críptica, anunció que Gernika sería destruida en $1937 \ldots$ o al menos, esa es la interpretación que se hizo de estas palabras suyas:

Cependant, les hordes castillanes ont fait irruption dans la Bizkaïe: le chêne vénérable, au pied duquel se tenaient, depuis trois mille ans, les assemblées de la république, est abattu. Sur la place où s'élevait l'arbre ibérien, les cagots ont écrit, dans la langue nouvelle, cette inscription digne des Barbares: ICI FUT GUERNIKA! ${ }^{15}$

\footnotetext{
11 Wordsworth, 1988 [escrito en 1810, publicado en 1815], sin paginar (mayúsculas en el original).

12 Liris, 1989.

${ }_{13}$ Caro Baroja, 1989 [1974], p. 391.

14 Ensunza Arrien, 2003, p. 226.

15 Chaho, 1865 [1836], pp. 91-92 (mayúsculas en el original).
} 


\section{Iparraguirre}

Y así llegamos al verdadero protagonista de esta historia. José María Iparraguirre Balerdi es el hombre providencial. Cantante, bohemio y guipuzcoano, estaba destinado a dar difusión universal a un símbolo originariamente vizcaino ${ }^{16}$.

Nacido en Urretxu en 1820, a los trece años se trasladó con su familia a vivir a Madrid. En 1834 tuvo lugar en la villa un motín anticlerical, en el que fue asesinado su profesor de latín, el padre Fernández. Este incidente marcó para siempre la vida de un ser de una profundísima fe católica. Ese mismo año se incorporó al ejército del Pretendiente durante la Primera Guerra Carlista. Llegó a ser alabardero, miembro de la guardia personal de don Carlos, y, como sus seguidores más exaltados, se negó a aceptar el Convenio de Bergara, de agosto de 1839, que puso fin a la guerra en tierras vascas. Marchó al exilio y no pudo regresar a España hasta 1852 .

Esos trece años en los que estuvo exiliado siguen siendo en gran parte un misterio. Residió en Francia, Italia, Suiza, Inglaterra y, posiblemente, algunos estados alemanes, países todos en los que se ganó la vida como músico ambulante (la castiza palabra castellana - y vasca - «arlote», con la que se le denominó Antonio Peña y Goñi ${ }^{17}$, es más descriptiva y tal vez más certera). No podemos detenernos en las múltiples aventuras, políticas y amorosas, que se le atribuyen. Es importante señalar que prácticamente todo lo que sabemos o creemos saber de Iparraguirre antes de alcanzar la celebridad lo conocemos gracias al propio interesado (o peor aún: a admiradores crédulos) y que por su propia vida nómada resulta muy complicado comprobarlo. Además de las letras de sus canciones, se conservan una treintena de cartas, pero, desgraciadamente, la más antigua de ellas es del año 1865, unos doce o trece años posterior al Gernikako Arbola. José Manterola, Juan Mañé y Flaquer, Nicolás de Soraluce, Fermín de Lasala y la sufrida esposa del Bardo, Ángela Querejeta, han aportado jugosos deta-

16 Para estas breves notas biográficas sobre Iparraguirre me he basado fundamentalmente en Manterola, 1877, pp. 3-7 y 1878, pp. 73-89; Mañé y Flaquer, 1879, pp. 358-372; Soraluce Zubizarreta, 1882, pp. 92-108; Lasala y Collado, 1924, I, pp. 320-347; Arrillaga Arriola (ed.), 1967 [1953]; Castresana, 1971; Euskaltzaindia, 1987; Mendibil (dir.), 1999, dos tomos, que incluye la correspondencia conservada de Iparraguirre; y Rubio Pobes, 2002, pp. 295-301.

17 Peña y Goñi, 1890, p. 260. 
lles sobre su vida, pero ninguno de ellos fue testigo de sus andanzas entre 1839 y 1852.

Vuelto del exilio, Iparraguirre residió en España entre 1852 y 1858 , pero al menos dos ${ }^{18}$ de esos años los pasó desterrado de las Provincias Vascongadas por orden del capitán general Manuel de Mazarredo, el mismo que había facilitado su regreso ${ }^{19}$. Entre 1858 y 1877 vivió en las Américas, sobre todo en Uruguay. Es una paradoja que, gracias a la magnífica entrevista que Francisco Grandmontagne mantuvo con la viuda del Bardo, en $1897^{20}$, y a los estudios de Justo Gárate ${ }^{21}$ y Mikel Ezkerro ${ }^{22}$ conozcamos bastante mejor los años de la etapa americana de Iparraguirre que los del exilio europeo. Murió en Itsaso (Guipúzcoa) en 1881, a la edad de 61 años, de los cuales solo unos 26 había pasado en su amada tierra vasca.

Decía que Iparraguirre es el hombre providencial. Según sus biografías, en mayo de 1835, participó en la batalla de Gernika (la misma que inspiró la supuesta profecía de Chaho), donde se apercibió del inmenso potencial simbólico del Roble ${ }^{23}$. Durante su exilio en Francia plantó árboles de la libertad ${ }^{24} \mathrm{e}$, incluso, conoció las doctrinas de Chaho ${ }^{25}$. Más tarde, en Inglaterra, le leyeron a Wordsworth ${ }^{26}$, como, se deja implícito, había leído a Tirso de Molina durante su infancia.

Esto, por lo menos, es lo que afirman sus biógrafos. Porque, ¿tenemos alguna prueba que avale la influencia de Tirso, de los árboles de la libertad, de Wordsworth, de la batalla de Gernika y de Chaho en Iparraguirre? Absolutamente ninguna. Es más: contra tal suposición se alza el testimonio del propio Iparraguirre de que desconocía el significado del Árbol de

18 «un par de años», según Soraluce Zubizarreta (1882, p. 96); «tres años», según Mañé y Flaquer (1879, p. 359)

19 La Capitanía General de la Provincias Vascongadas existió entre 1836 y 1893. A lo largo de su alambicada historia incluyó a Navarra en varias ocasiones, aunque no en la época que nos ocupa. Ordenación..., 2004, pp. 11-14.

20 Grandmontagne, 1999 [1897].

${ }^{21}$ Gárate Arriola, 1987.

22 Ezkerro, 1999.

23 Arana Martija, 1987, p. 287.

${ }^{24}$ Olaso y Aguirre, 1999, pp. 74-75.

25 Olaso y Aguirre, 1999, p. 72. Iparraguirre trató incidentalmente a Chaho, quien recopiló un cancionero vasco e incluso transcribió la letra de la canción Gitarra zartxo bat del Bardo, pero el suletino no tiene noticia del Gernikako Arbola, ni siquiera cita por su nombre al guipuzcoano. Chaho, 1855, II, pp. 155-156.

${ }^{26}$ Castresana, 1971, pp. 46 y 80. 
Gernika hasta que volvió del exilio. Así lo expone el vascófilo catalán Mañé y Flaquer, reproduciendo literalmente las palabras del Bardo:

Hizo la travesía de Inglaterra á España en un bergantín que estuvo á punto de perderse antes de llegar a Santoña. Pasó de allí á Bilbao, donde fue recibido con grande agasajo por la juventud vizcaina. «En aquella época no sabía lo que eran los fueros, dice con muchísima ingenuidad el vate guipuzcoano en una carta suya que tengo á la vista, $-\mathrm{y}$ un jóven ilustrado me explicó lo que significaba el árbol de Guernica. Me entusiasmé, y aquella misma noche canté lo que más tarde ha cantado todo el país» ${ }^{27}$.

Iparraguirre no da ninguna fecha para datar su conversión al fuerismo, pero obviamente la sitúa en $1852^{28}$, recién llegado de Inglaterra y poco antes de componer el Gernikako Arbola. De manera incomprensible, esas palabras del propio Iparraguirre, de las escasas que podemos atribuirle con certeza fuera de su correspondencia, han sido manipuladas. Así, en uno de sus biografías más conocidas, esa cita queda redactada así:

En aquella época en que fui voluntario carlista yo no sabía lo que eran los fueros... ${ }^{29}$

Al interpolar el sintagma «en que fui voluntario carlista» el sentido de la frase cambia por completo. La conversión del Gran Arlote al fuerismo deja de ser datada en 1852 para retrotraerse a 1834-1839. Al parecer, a algunos resulta difícil de digerir que Iparraguirre, como muchos otros carlistas vascos, no hubiera luchado por los fueros, sino por el rey absoluto y la alianza entre el Trono y el Altar. Si, como se ha supuesto, llegó a participar en la batalla de Gernika, de mayo de 1835, lo cual está por demostrar, en aquella época el Roble carecía de todo significado para él, como para todos los demás vascos no vizcainos, excepción hecha de algún visionario como Chaho.

27 Mañé y Flaquer, 1879, p. 359. Por eso carece de todo fundamento la pretensión de Bernadou (1894, pp. 60-61) de que Iparraguirre ya había compuesto el Gernikako Arbola para 1842 o 1843 y que lo cantó en Larresoro, Labort, en 1845 o 1846.

28 Para conocer el ambiente político que se vivía en los territorios vascos en 1852, el año de los frustrados proyectos de arreglo foral de Bravo Murillo, Vázquez de Prada, 1984, pp. 208-217 y 483-496.

${ }_{29}$ Olaso y Aguirre, 1999, p. 49; las cursivas son mías. 


\section{Altuna y la música}

La primera interpretación del Gernikako Arbola se documenta en el Café San Luis de Madrid, en fecha indeterminada del año 1853, pero, con toda probabilidad, antes del 30 de junio $^{30}$. Como se ha señalado, sabemos que Iparraguirre fue desterrado de las Provincias Vascongadas por Mazarredo, durante unos dos años, a causa de los disturbios que solían producirse tras sus recitales. La versión tradicional de su biografía apunta a que ese destierro se inició en 1855, durante el Bienio Progresista $^{31}$. Sin embargo, en su correspondencia, Iparraguirre parece fechar su comienzo más bien hacia 1852, durante la Década Moderada ${ }^{32}$. De ser cierto, eso significaría que la presentación pública del Gernika se produjo antes de la actuación del Café San Luis, posiblemente en 1852 en Vasconia, tal vez en Bilbao ${ }^{33}$. Dejando a un lado las fechas, lo sustancial es que el Gernikako Arbola conoció un éxito fulminante, tanto en la propia Vasconia, como en las comunidades vascas del exterior. Pudo influir en ello, más que su poderosa voz de barítono, el hecho de que, si estas cuentas son correctas, en 1853 Iparraguirre era un proscrito, un desterrado de su país, en otras palabras, un mártir de la causa fuerista, a la que, no lo olvidemos, se había adherido tan solo unos meses antes.

30 Arana Martija (1999, p. 108) constata una interpretación del Gernikako Arbola el 30 de junio de 1853 en la Universidad de Madrid, en un acto de doctorado. Al parecer sería posterior a la del Café San Luis.

31 Manterola, 1877, p. 5 y 1878, pp. 78-79; Arrillaga Arriola (ed.), 1967 [1953], p. 262; Castresana, 1971, pp. 83-85.

32 Olaso y Aguirre, 1999, p. 85. Iparraguirre, en una carta a Antonio Trueba, fechada en febrero de 1871, data su destierro 20 años antes de la fecha. Carta a Antonio Trueba, célebre escritor bilbaíno (Mercedes, Uruguay, 20 de Febrero de 1871), en Mendibil, 1999, I, pp. 200-201 (200). En otra carta, esta vez a sus amigos vitorianos, de mayo de 1877, lo sitúa 25 años antes. Carta y versos a sus amigos de Vitoria, Julián y Ricardo Becerro de Bengoa, Sotero Manteli, Daniel de Arrese y Fermín Herrán (Costa del Arroyo El Dacá, Mercedes, Uruguay, 4 de Mayo de 1877), en Mendibil, 1999, I, pp. 205-206 (206). Ambas cartas nos hacen pensar que el extrañamiento de las Vascongadas tuvo lugar en 1852 (en 1851, según la cronología que se sigue en este artículo, se hallaba en Francia e Inglaterra), es decir, al poco de llegar del exilio y antes del recital del Café San Luis de Madrid.

${ }^{33}$ Soraluce Zubizarreta (1882, p. 96) afirma que el himno fue compuesto en Bilbao, recién llegado Iparraguirre del exilio. Si está en lo cierto, parece lógico pensar que el primer recital fuera también en la villa. 
El Gernikako Arbola es un zorcico, un ritmo de baile en 5/8 típico de Vasconia. En su primera interpretación conocida, Iparraguirre estuvo acompañado al piano por Juan María Blas de Altuna (1828-1868). Poco después surgieron rumores de que el compositor durangués era su verdadero autor ${ }^{34}$. Contra esta suposición consta el testimonio de Iparraguirre, quien siempre asumió la autoría de la melodía, y, ex silentio, el de Altuna, quien nunca reivindicó para sí tal honor y eso que tuvo oportunidad de hacerlo, ya que Iparraguirre residió en las Américas desde 1858. No tenemos argumentos para dudar de la versión del Bardo, quien afirma que Altuna se limitó a transcribir la melodía «enmendando tal vez algunas faltitas ${ }^{35}$. Uno de los muchos partidarios de la autoría de Altuna fue Sabino Arana ${ }^{36}$.

Y, al menos durante un tiempo, en esas estábamos cuando José Antonio Arana Martija defendió la teoría de que ni Iparraguirre ni Altuna eran los autores de la música del Gernikako Arbola. Para este estudioso, se trata de la adaptación de una melodía popular de Garai, en el Duranguesado, que forma parte del ciclo Dantzari-dantza y que se documentaría ya en 1711. Iparraguirre (¿o sería Altuna?) podría haberla escuchado en sus correrías por la zona durante su época como voluntario carlista ${ }^{37}$.

\section{La letra}

En su versión actual, que es la que ya recoge José Antonio Santesteban en su Colección de aires vascongados (1862), el Gernikako Arbola consta de doce estrofas (bertsoak, en euskara) ${ }^{38}$. Las cuatro últimas son denominadas en el propio himno «bertzo [sic] berri», esto es, nuevas, lo que significa que no formaban parte de la versión original. Dado que la estrofa decimosegunda está dedicada a la Virgen, es posible deducir que

${ }^{34}$ Manterola, 1878, pp. 76-78.

${ }^{35}$ Carta a un amigo, que también lo era de Antonio Trueba (Durango, 17 de Octubre de 1878), en Mendibil, 1999, I, p. 217.

${ }^{36}$ La posición de Sabino Arana respecto a la autoría del Gernikako Arbola era dubitativa y contradictoria, como se puede comprobar hojeando Bizkaitarra. El 14 de septiembre de 1893 se refiere al «inmortal himno patrio del olvidado Altuna». Solo tres meses más tarde, el 10 de diciembre, habla del «glorioso himno de Altuna é Iparraguirre». Ya el 19 de febrero de 1894 establece que es «el inmortal himno del insigne Iparraguirre».

37 Arana Martija, 1987, p. 289 y 1999, p. 108; y Sánchez Ekiza, 2007.

38 Santesteban, 1862, n. $^{\circ} 2$. 
las cuatro se añadieron con motivo de la proclamación del dogma de la Inmaculada Concepción, el 8 de diciembre de $1854^{39}$.

El Gernikako Arbola posee la inusual capacidad de emocionar a personas de ideologías muy diversas. Lo han entonado sin distingos carlistas, liberales, republicanos y socialistas, además de nacionalistas vascos y navarristas, a quienes dedicaré sendos apartados en este trabajo. Antonio María Labayen señaló la continuidad entre la letra del himno y la empresa de Muñagorri al final de la Primera Guerra Carlista ${ }^{40}$. Como se recordará, José Antonio Muñagorri intentó desvincular el mantenimiento de los fueros de la causa del Pretendiente. En gran parte gracias a él, la Ley Vieja se identificó con la paz entre carlistas y liberales, una idea que está muy presente en el Iparraguirre maduro (en 1839, por el contrario, había repudiado el Convenio de Bergara, en el que se concretaron los esfuerzos de Muñagorri). Solo por ese pacifismo innato, el zorcico habría pasado a la historia cultural vasca. Pero es que Iparraguirre va más allá. En él, el Árbol de Gernika se convierte en la encarnación misma de los fueros y de la unidad de Vasconia, una unidad alejada de toda tentación aislacionista, perfectamente compatible con una concepción universal y humanista de lo vasco. Así leemos en la primera estrofa:

Guernicaco arbola

Da bedeincatuba,

Eeuscaldunen [sic] artean

Guztiz maitatuba:

Eman ta zabaltzazu

Munduban frutuba,

Adoratzen zaitugu

Arbola santuba ${ }^{41}$.

Y, por encima de todo, algo en lo que no se suele incidir, el Gernikako Arbola es un himno religioso. Iparraguirre fue un fuerista accidental (ya se ha dicho que no supo qué eran los fueros hasta que volvió del exilio). La piedra angular de su pensamiento es el catolicismo, lo

39 Haritschelhar, 2000.

40 Labayen, 1972, p. 370, nota 1.

41 «El árbol de Gernika/ Es bendito,/ Muy amado/ Entre los vascos: Da y expande/ Tu fruto por el mundo,/ Te adoramos/ Árbol santo». Las citas del Gernikako Arbola, incluyendo la ortografía, las tomo de Santesteban. Las traducciones son mías. 
que le distingue de los republicanos de la época, con los que a menudo se le compara. Dios, con diversos nombres (Jaincoa, Jauna y Jaungoico jauna), es mencionado cuatro veces y la Virgen María (Ceruco erreguiña) en una ocasión más. Cristo no aparece como tal, pero su presencia se deja sentir a lo largo de todo el himno. Los términos de clara significación religiosa son también muy abundantes: bedeincatuba («bendito»), Adoratzen zaitugu («te adoramos»), santuba («santo»), belaunico («de rodillas»), Mancha gabecoa («sin mancha»), Erruquisaitez («compadécete»), Erregutu diogun («roguémosle»), bendiciyoa («bendición»)... El Gernikako Arbola es un himno confesional católico. Nadie, por muy fuerista que sea, se arrodilla ante el Árbol de Gernika: el Roble es un trasunto del crucifijo. Tampoco es que haya que exagerar la originalidad de Iparraguirre en este punto, pues desde 1643, por lo menos, el Árbol de Gernika viene acompañado por una cruz en el escudo de Vizcaya $^{42}$.

En el primer libro de la Biblia (Génesis, 2:9), se narra que Dios colocó en el Edén el Árbol de la Vida y también el Árbol de la Ciencia del Bien y del Mal, con el que a veces se identifica. Iparraguirre nos cuenta en la segunda estrofa de su himno que Dios plantó su Árbol en Gernika hace unos mil años. En la mente de Iparraguirre el árbol edénico (o, si se prefiere, los dos árboles edénicos) y el vizcaino son prácticamente sinónimos. Pero la influencia bíblica no termina ahí. Según una tradición que se remonta a Tertuliano (c.160-c.225), la Cruz (lignum crucis) donde murió Cristo era una representación del Árbol de la Vida del Paraíso: «quod perierat olim per lignum in Adam, id restitueretur per lignum Christi» ${ }^{43}$. Así se establece una analogía perfecta entre el Edén, el Gólgota y Gernika. Precisamente el peso de la religión (más específicamente, del catolicismo) en Iparraguirre debería poner en cuestión su republicanismo durante su exilio en Francia, donde esa ideología tenía en su época una clara connotación laica y anticlerical.

La palabra paque («paz») aparece en tres ocasiones en el Gernikako Arbola, a las que hay que añadir las dos en que se menta, para condenarla, la palabra guerra. Por contra, la palabra «libertad» no se menciona ni una sola vez en las doce estrofas, algo llamativo en un himno

42 Guerra, 1927, p. 304. Según Guerra, el escudo de Vizcaya incluye una cruz roja en fondo de plata (blanco). Los hermanos Arana Goiri invertirían los colores al diseñar la ikurriña en 1894.

${ }^{43}$ En Lukken, 1973, p. 86, nota 23. 
patriótico. He ahí un argumento para poner en cuarentena la versión tradicional que pretende que Iparraguirre plantó árboles de la libertad durante la Revolución de 1848. Si lo hizo, algo de lo que no tenemos constancia, está claro que no veía conexión alguna entre ellos y el Roble de Gernika. El antecedente inmediato del Gernikako Arbola no es el Árbol de la Libertad, como se ha supuesto, sino el Árbol de la Vida y la Cruz de Cristo.

Iparraguirre escribe en un euskara guipuzcoano popular ${ }^{44}$, lleno de castellanismos, muy alejado del purismo de los primeros nacionalistas vascos. Esa será una de las razones - aunque no la única, como se verádel desdén de Sabino Arana por Iparraguirre y su obra. Arana Goiri, nacionalista, concibe el euskara como una barrera contra la influencia extranjera, así que para él resultaba fundamental extirpar los préstamos del castellano. Para Iparraguirre, fuerista, la lengua es, ante todo, un medio de comunicación que, por tanto, no debe temer asimilar voces procedentes del castellano y otros idiomas, especialmente el latín. Las ideologías políticas de ambos se plasman en el idioma.

El uso, ya desde el título, de arbola en lugar de zuhaitz provocó una polémica cuyos ecos perduran en nuestros días. Vinson y Unamuno, entre otros, llegaron al extremo de negar que en euskara pudiera expresarse el concepto de «árbol», como probaría el propio himno de Iparraguirre. Tales afirmaciones llevaron a algunos nacionalistas vascos a posicionarse en el extremo contario y exagerar la capacidad del vascuence para expresar conceptos generales, en especial el de «árbol». Bernardo Estornés Lasa encontró 8 supuestos sinónimos de «árbol» en lengua vasca y Justo Gárate fue incluso más lejos, ya que encontró nada menos que otros 11 vocablos. Reproduzco ambas listas en nota a pie de página $^{45}$. No hará falta insistir en que la mayoría de esas 19 voces no significan «árbol», sino un tipo de árbol en concreto o la parte de un árbol. Casi todas las demás, salvo zuhaitz y sus variantes, son voces desconocidas para los vascófonos de hoy en día (y de siempre) o, en todo caso, de extensión reducidísima.

${ }^{44}$ La palabra juntia, en la tercera estrofa, podría ser el único testimonio del dialecto vizcaino (en guipuzcoano es junta, como en castellano), pero también podría ser forzada por la rima.

${ }^{45}$ Los nombres documentados por Estornés son zugaitz, usi, tantai, ezkur, garrazta, sabi, txirpi y landai. Los de Gárate son galar, errexala, ondo, atze, el o le, ur, gabil, zubil, zuhain, txerto y aba. Gárate (Arriola), 1973 y 1987, p. 234. 
Ni Vinson ni Unamuno en un extremo, ni Estornés ni Gárate en el otro querían aceptar la evidencia. Que en vascuence actual existen dos palabras para decir «árbol»: arbola y zuhaitz, ambas con sus variaciones dialectales (incluida zuhamu, no incluida en las listas de estos autores). A ellas se podría añadir errexal, voz recogida por Niccolò Landucci en 1562, pero en desuso desde hace siglos, así como haritz, hoy solamente «roble», pero que fue bastante usado, sobre todo en su variante vizcaina aretx, en el sentido de «árbol». Aunque se podría matizar que, según Silvain Pouvreau, que escribe hacia 1665, arbola más que «árbol» en general significa «árbol frutal» ${ }^{46}$. De acuerdo con esa feliz acepción, el Árbol de Gernika es un arbola porque da y expande su fruto por todo el mundo. No creo que Iparraguirre fuera consciente del matiz introducido por Pouvreau y autores posteriores. Tal vez desconocía el vocablo zuhaitz. O tal vez no le parecía adecuado para referirse al Árbol Santo, dado que zuhaitz significa, estrictamente hablando, «árbol bravío, árbol de madera». El caso es que, con intención o sin ella, al preferir arbola a zuhaitz, el genio de Iparraguirre dotó al himno dedicado al Viejo Roble de una inmensa fuerza poética.

\title{
5. «Himno nacional»
}

Iparraguirre compuso su himno pensando en las cuatro provincias vasco-españolas, es decir, también en Navarra. El lema del Laurak Bat («las cuatro provincias son una sola»), utilizado por los carlistas por lo menos desde $1846^{47}$, aparece de modo implícito en el himno

\author{
Lauroc artuco degu \\ Surequin partia \\ Paquian bicidedin \\ Euscaldun gendia ${ }^{48}$
}

46 Pouvreau, manuscrito, datado hacia 1665, p. 20.

47 Martínez Beloqui, 1984, p. 464, nota 9.

48 «Las cuatro [provincias]/ Tomaremos parte contigo/ Para que el pueblo vasco/ Viva en paz» (tercera estrofa). Sin embargo, Navarra no es mencionada en el himno. De hecho, solo Vizcaya aparece citada por su nombre en la versión original (tercera estrofa). Las menciones a Álava (novena estrofa) y Guipúzcoa (décima) fueron añadidas c. 1854 con los bertzo berri. 
y, ya explícitamente, en una carta de Iparraguirre al Ayuntamiento de su localidad natal en 1869:

Tampoco a mí me disgustaría la federal de Laurac-bat, que estoy cierto sería el modelo; sin perder en nada, nuestra sagrada fe católica, y nuestras patriarcales costumbres ${ }^{49}$.

Navarra forma parte ineludible de la cosmovisión del Bardo ${ }^{50}$. Más adelante me detendré en las consecuencias de esta constatación.

Ya me he referido al éxito instantáneo del Gernikako Arbola. Tan solo dos años después del recital del Café San Luis, en 1855, dos fuentes independientes lo denominan «himno nacional». El articulista de La España (Pedro de Egaña, fundador y director de la publicación) parece incluir solo a Álava, Guipúzcoa y Vizcaya en esa nación «vascongada»:

si no existiera la tradicional marcha de San Ignacio pudiera llamarse el himno nacional de los vascongados ${ }^{51}$.

Justin Cénac-Moncaut, en cambio, compara el roble de Gernika con el de Ustaritz, bajo el que se reunían las asambleas labortanas:

Le chant national suivant joint à une certaine valeur poétique l'intérêt historique que doit naturellement exciter l'arbre colossal et séculaire auquel il est dédié, et sous lequel la junte d'Alava [sic!] tint ses réunions pendant plusieurs siècles, comme la Bilzaar se réunissait sous le chêne d'Uustaritz [sic ${ }^{52}$,

49 Carta y versos al Ayuntamiento de Villareal de Urretxu, su pueblo natal en Guipúzcoa (Mercedes, Uruguay, 1 de Septiembre de 1869), en Mendibil, 1999, I, p. 199.

50 Iparraguirre conoció Navarra durante la Primera Guerra Carlista. Como alabardero, tuvo que estar cerca de don Carlos, que durante una época estableció su Corte en Estella. Además, fue herido en Mendigorría, donde estuvo a punto de caer prisionero. En sus últimos años estuvo en contacto con la Asociación Euskara de Navarra, especialmente con Arturo Campión. De manera directa o indirecta, además de en Gernikako Arbola, Navarra aparece por lo menos en sus poemas y canciones siguientes: Bilbao eta Fueruak Pakearentzat (1876), Obian (1878), Mairuen bandera (1878), Nafarroako Alkarkidari (1878) y Nafarren Elkargoari (1879).

51 [Egaña], 1855.

52 Cénac-Moncaut, 1855, p. 324. 
lo que induce a pensar que el zorcico empezaba a ser conocido en las provincias vascas al norte del Pirineo ${ }^{53}$. Resulta sorprendente la velocidad con la que se difundió por toda Vasconia, del Ebro al Adur. En el Gernikako Arbola no se hace ninguna alusión a los territorios vascos continentales. Sin embargo, durante su exilio en Francia (1839-1851), Iparraguirre conoció al menos Labort ${ }^{54}$. Y, durante su larga estancia en América (1858-1877), trató, sin duda, con muchos vasco-franceses (entre ellos, acaso, Domingo Elutchauz o Elutchanz, el amante y segundo esposo de su mujer). Sin fronteras que les dividieran, en una época en la que el vascuence estaba mucho más vivo que en la actualidad, vasco-españoles y vasco-franceses tendían a formar una sola comunidad en la Diáspora ${ }^{55}$. Como describe, no sin cierta añoranza, desde Urretxu al poco de volver del Nuevo Mundo,

Hasta los mismos vascos franceses se conduelen de nuestro abatimiento y de nuestra desgracia, y ¿qué tiene eso de extraño? La misma sangre circula en sus venas ${ }^{56}$.

Y ahora urge una puntualización. Y es que para Iparraguirre, como para los fueristas de su tiempo, el sentimiento de pertenencia a Euscal erria, término que aparece dos veces en el Gernikako Arbola, es compatible con el de pertenencia a España (o, en su caso, a Francia). En 1877, a su vuelta de casi 20 años de periplo por tierras americanas, al divisar

53 Ya en los juegos florales de Urruña, en Labort, en 1858, se presentó una composición titulada $O$ Gernikako haritz (Oh, roble de Gernika), con la música del Gernikako Arbola. Jean-Pierre Duvoisin afirma en 1868 que el himno de Iparraguirre todavía no era muy conocido en las provincias vasco-francesas. Sin embargo, entre 1858 ya 1900 , la música del Gernikako Arbola es la más utilizada en los Juegos Florales de la Vasconia continental, en un total de diez ocasiones. Haritschelhar, 2000.

${ }^{54}$ Aunque hay que tomar su testimonio con cautela, pues se refiere a acontecimientos acaecidos medio siglo antes, Gratien Adéma «Zalduby» (en Bernadou, 1894, pp. 60-61) afirma que Iparraguirre estuvo en Larresoro, en 1845 o 1846. Chaho (1855, II, pp. 155156), que residía en Bayona, cuenta que Iparraguirre se le presentó recién llegado de Italia, aunque no concreta la fecha. Peña y Goñi (1890, p. 261) tampoco da la fecha del supuesto recital de Iparraguirre en San Juan de Luz.

55 Álvarez Gila, 1999.

56 Carta a Miguel Loredo, director de La Paz de Madrid (Villarreal de Urrechua, 20 de Noviembre de 1877), en Mendibil, 1999, I, p. 209. 
la costa guipuzcoana desde Hendaya, proclama ${ }^{57}$ : «allí está España [no «Euskadi», como cantan algunos manipuladores ${ }^{58}$ ], Europa no tiene una tierra mejor». El Bardo era muy vasquista, pero también muy españolista, y condenó sin ambages el único movimiento separatista que llegó a conocer: el cubano ${ }^{59}$.

Iparraguirre, como el roble que inmortalizó y que le inmortalizó, es hoy un símbolo. Resulta muy difícil distinguir la persona del personaje. Con demasiada ligereza, se suele suponer que vuelve republicano de su exilio. Más acertado sería que el Iparraguirre maduro era indiferente respecto al régimen político. El equívoco se debe, aparte de a la devoción que al parecer profesaba a La Marsellesa, a la que me referiré enseguida, a su ambigua simpatía por el federalismo. Sin embargo, ese federalismo laxo bebe más del fuerismo o incluso de la tradición descentralizadora carlista que de un republicanismo consecuente:

Eman da Zabalzazu munduan frutua: parece que han comprendido nuestros hermanos de allende del [sic] Ebro; pues también proclaman sus fueros; el árbol esta [sic] dando su fruto y la semilla que se ha esparcido brota $^{60}$.

Cuando escribe esta carta España se encuentra en pleno Sexenio. Sin embargo Iparraguirre evita realizar manifestación alguna de republicanismo (y de monarquismo también, es cierto). Parece como si en el terreno político quisiera mantenerse neutral a toda costa. Para 1869, cuando redacta estas líneas, Iparraguirre, residente en Uruguay y fracasado en su vida profesional y familiar, lleva años intentando volver a España y para

57 «Hendayan nago choraturican/ zabal-zabalic beguiac;/ ara, España, lur oberican/ ez du Europa guciac». Iparraguirre, 1999 [1877].

58 Ya se ha dicho que Euzkadi es un neologismo creado por Sabino Arana en 1896, así que es imposible que Iparraguirre lo utilizara. Linazasoro (1977, p. 45) manipula el texto de Nere etorrera lur maitera, sustituyendo España por Euskalerri, que rompe el verso.

59 Por no alargarnos en este tema, solo citaré una frase, muy significativa, de Iparraguirre, escrita con motivo de la Guerra de los Diez Años: «absténgase todo buen Español, de pronunciamientos; sea en sentido carlista, ó sea en el Republicano, á lo menos hasta que se sofoque la insurrección de La Havana...». Carta y versos al Ayuntamiento de Villareal de Urretxu, su pueblo natal en Guipúzcoa (Mercedes, Uruguay, 1 de Septiembre de 1869), en Mendibil, 1999, I, p. 199.

${ }^{60}$ Carta y versos al Ayuntamiento de Villareal de Urretxu, su pueblo natal en Guipúzcoa (Mercedes, Uruguay, 1 de Septiembre de 1869), en Mendibil, 1999, I, p. 199. 
eso resultaba imprescindible no crearse enemigos. Se distanciará públicamente del carlismo insurgente y solo se referirá a los dos elementos que, según él, unen a todos los vascos: el catolicismo y los fueros. Cuando regrese definitivamente a Vasconia en 1877 dedicará sus esfuerzos a conseguir una pensión de las cuatro diputaciones.

\section{6. ¿Una Marsellesa vasca?}

En el imaginario colectivo vasco Iparraguirre está ineludiblemente asociado con La Marsellesa. La versión canónica de esa relación, como no podía ser menos, se debe a un republicano, el escritor alavés Ricardo Becerro de Bengoa, corresponsal del vate guipuzcoano, quien apunta en 1879:

Como electrizó un día a los vascongados cantando en medio de las campas de las romerías el himno al Roble Santo, así sacudió el entusiasmo de los demócratas franceses entonando la Marsellesa en las jornadas del 48; y así hizo sentir al pie de los Alpes, en los populares conciertos, cómo los cantores españoles saben entrelazar deliciosamente los acordes de la guitarra con la tierna cadencia de las cántigas [sic] nacionales. Sus muchos arrebatos musicales de las provincias le valieron dos o tres destierros de España; sus ecos en Toulouse le arrojaron de Francia, después de pasar por ochenta cárceles ${ }^{61}$.

Becerro de Bengoa, imbuido de espíritu romántico, olvida entre tanta hipérbole consignar lo fundamental: quién y cuándo expulsó a Iparraguirre del territorio francés. Esos detalles serán concretados por otros exégetas de la vida del Bardo.

Según Mañé y Flaquer, que escribe antes de Becerro, cuando Iparraguirre acaba de instalarse definitivamente en España,

En tiempo del [Segundo] Imperio [Francés], los republicanos le hacían cantar la Marsellesa, lo cual producía grande entusiasmo, y algunas veces ocasionó riñas entre republicanos é imperialistas; de resultas de lo cual el gobierno francés le expulsó del país ${ }^{62}$.

${ }^{61}$ Becerro de Bengoa, 1967 [1879], p. 137.

62 Mañé y Flaquer, 1879, p. 359. 
Nicolás de Soraluce, quien publica su libro en 1882, cuando el Bardo había ya fallecido, sigue a todas luces a Mañé:

en tiempos del Imperio los republicanos le hacían cantar la Marsellesa, que la ejecutaba á las mil maravillas. A la vez era causa del entusiasmo que producía en los concurrentes, surgiendo más de una vez riñas entre la muchedumbre de republicanos é imperialistas. Y resultado de esto el que el Gobierno Francés lo expulsara del país ${ }^{63}$.

Finalmente, en la entrevista concedida a Francisco Grandmontagne en 1897, Ángela Querejeta, viuda de Iparraguirre, no añade nada que no sepamos ya:

el Gobierno francés le echó de Francia porque, cuando Joshe Mari la cantaba [La Marsellesa, XZ], la gente del pueblo se iba detrás de él dando gritos revolucionarios. El rey de los franceses no le podía ver. Y la reina, que era una española, aunque no vasca, tampoco ${ }^{64}$.

En el relato de Querejeta existen, además, varias imprecisiones que hay que poner de manifiesto. En primer lugar, Louis-Napoléon Bonaparte nunca se tituló «rey de los franceses». En segundo lugar, Eugenia de Montijo solo se convirtió en emperatriz, que no en reina, en enero de 1853, casi dos años después de los hechos narrados.

Pero más significativo que estas vaguedades y estos lapsus es que Iparraguirre no haga alusión a La Marsellesa cuando de la manera más escueta posible cuenta este incidente en una carta de 1876, tal solo unos meses antes de instalarse definitivamente en España: «mi destierro á Inglaterra por el Gobierno de Napoleón; el recibimiento que me hicieron en Londres los patriotas emigrados franceses» ${ }^{65}$. Ni una sola palabra más en toda su correspondencia. Y hay que añadir que ni Becerro, ni Mañé, ni Soraluce (a pesar de que era amigo del Bardo desde la infancia), ni Querejeta (que conoció a su futuro esposo en 1855 o 1856) fueron testigos de estos hechos. Tampoco puede silenciarse la contradicción en las fechas.

63 Soraluce Zubizarreta, 1882, p. 94.

64 Grandmontagne, 1999 [1897], p. 181.

65 Carta a Enrique Romero Jiménez, director de El Correo Español de Buenos Aires (Mercedes, Uruguay, hacia 10 de Noviembre de 1876), en Mendibil, 1999, I, p. 203. Tampoco Manterola, el primero de sus biógrafos, hace alusión a La Marsellesa para explicar la presencia de Iparraguirre en Londres. 
Es cierto que La Marsellesa fue cantada por los oponentes al golpe de estado que Bonaparte dio el 2 de diciembre de 1851 y que estuvo prohibida durante gran parte del Segundo Imperio Francés ${ }^{66}$. La cuestión es que los tres primeros biógrafos de Iparraguirre coinciden al señalar que este participó en la Exposición Universal de Londres, que tuvo lugar entre mayo y octubre de 1851, es decir, que se encontraba en la capital británica desde varios meses antes del golpe ${ }^{67}$. Con la navaja de Ockham en la mano, la manera más sencilla de hacer concordar el breve testimonio de Iparraguirre con estas fechas es que fue deportado siendo Bonaparte presidente constitucional de la República (antes del golpe y, por ende, antes de proclamarse emperador) cuando La Marsellesa era perfectamente legal en Francia. A falta de pruebas concluyentes, la expulsión de Iparraguirre de Francia por Bonaparte a causa, según se ha supuesto, de los tumultos que seguían a la interpretación de La Marsellesa resulta sospechosamente similar a su expulsión de las Provincias Vascongadas por Mazarredo a causa de los tumultos que seguían a la interpretación del Gernikako Arbola. Suena a un déjà vu, una recreación tardía del Bardo, convertido ya en un mito, o, más probablemente, de sus mitificadores.

Y es que es difícil imaginar un himno más opuesto a La Marsellesa que el Gernikako Arbola. El de Rouget de Lisle es una llamada a la violencia revolucionaria. Por el contrario, el pacifismo es el pilar que sustenta el de Iparraguirre y tal vez la razón principal de su éxito arrollador. Ahora bien, ¿la letra que se conserva de este es la primitiva, o existió otra anterior? Ya me he referido a Pedro de Egaña. Siendo senador, en 1864, Egaña, dirigiéndose a sus señorías, tradujo al castellano la letra y la versión que da resulta sorprendente:

y pedimos al cielo que si la tempestad azota tus ramas frondosas, y gentes extrañas vienen a destruir tu tronco, el hierro salvador que contienen los senos de nuestros montes se convierta en armas aceradas de todas clases para defenderte ${ }^{68}$.

Como puede comprobarse, se trata de una letra belicista, muy distinta de la que conocemos. Algunos han deducido de ello que Egaña reproduce

\footnotetext{
66 Vovelle, 1997 [1984-1992], I, pp. 107-152, especialmente pp. 133-134.

${ }^{67}$ Manterola, 1877, p. 4; Mañé y Flaquer, 1879, p. 359; Soraluce Zubizarreta, 1882, p. 94.

68 Egaña, 1967 [1864], p. 246.
} 
la letra original, que Iparraguirre modificó posteriormente. José Francisco Olaso y Juan Aguirre han imaginado incluso

la existencia de una primera versión del Gernikako Arbola, quizás no radicalmente distinta de la actual, pero con variantes combativas y sediciosas (en la línea de La Marsellesa y de los cantos de tropa) que resultaban especialmente provocativas por ser su autor un ex combatiente carlista ${ }^{69}$.

En mi opinión, por el contrario, hay razones para pensar que se trata de un error, bien de Egaña, bien del transcriptor de su discurso. La principal es que las primeras versiones conservadas del Gernikako Arbola, la de Cénac-Moncaut $(1855)^{70}$ y la de Michel $(1857)^{71}$, aunque parciales (ambas reúnen solo cuatro estrofas), coinciden con la actual y no dan muestra alguna de belicismo. Por eso considero altamente improbable que los versos que menciona Pedro de Egaña en el Senado en 1864 sean obra del urretxuarra. Además, Egaña, en el texto citado, da a Iparraguirre por muerto en Montevideo, así que no parece estar muy bien informado ${ }^{72}$. Es posible, sin embargo, que en el discurso de Egaña resuenen los ecos de otro poema dedicado al Árbol de Gernika.

José Miguel de Arrieta-Mascarúa (1817-1869) fue un prócer carlista de Güeñes, en las Encartaciones, diputado general del Señorío de Vizcaya entre 1856 y 1858. Iparraguirre se alojó en su casa antes de partir para Santander hacia el destierro, sea en 1852 o en 1855. Arrieta-Mascarúa es el autor de una oda dedicada al Árbol de Gernika. Esta obra impresionó a Iparraguirre, quien, según relata en una carta, conservó el original «como santa reliquia» ${ }^{73}$. Sabino Eguidazu y Manuel Basas incluso supusieron que fue Arrieta-Mascarúa el autor de la letra del Gernikako Arbola ${ }^{74}$. Si se

69 Olaso y Aguirre, 1999, p. 114.

70 Cénac-Moncaut, 1855, p. 324.

71 Michel, 1857, pp. 262-263.

72 No es el único error de Egaña, quien afirma que Iparraguirre contaba con 16 años cuando se incorporó al ejército del Pretendiente (en realidad tenía 14) y que vivió en el exilio en Francia durante 20 años (en realidad fueron 12 como máximo). Si se lee su discurso, la sensación general es que habla de oídas.

${ }^{73}$ Carta y versos a sus amigos de Vitoria, Julián y Ricardo Becerro de Bengoa, Sotero Manteli, Daniel de Arrese y Fermín Herrán (Costa del Arroyo El Dacá, Mercedes, Uruguay, 4 de Mayo de 1877), en Mendibil, 1999, I, pp. 205-206 (206).

74 Olaso y Aguirre, 1999, p. 112; Arana Martija, 1999, p. 107. 
lee la última estrofa de su poema, se apreciará que nos encontramos ante un himno bélico, que no tiene nada que ver con el Gernika:
Ah! mientras que el sol alumbre
Las cimas de estas montañas,
$Y$ se encierre en sus entrañas
El acero matador,
Eterno será el renombre
Del gran árbol de Guernica,
Y su historia siempre rica
De virtudes y de honor ${ }^{75}$.

¿Fue ese poema el que leyó Egaña en las Cortes, confundiéndolo con el de Iparraguirre? Es una posibilidad, aunque remota, ya que el senador advierte en su alocución que estaba traduciendo el texto desde el vascuence y Arrieta había escrito el suyo en castellano. Si no se trata, sin más, de una pura invención de Egaña ${ }^{76}$, otra posibilidad es que, como es habitual en el versolarismo, la música del Gernikako Arbola se utilizara para acompañar otros cantos, algunos de ellos revanchistas. Desde luego, Iparraguirre, que por lo menos desde la vuelta del exilio ha apostado claramente por la reconciliación entre carlistas y liberales, no pudo ser su autor.

No puedo menos que terminar este apartado afirmando que el texto de Iparraguirre es infinitamente superior al de Arrieta-Mascarúa. Este nunca podría haber constituido la letra de un himno para Vasconia fundamentalmente por tres razones. En primer lugar, porque en el poema del tradicionalista encartado solo se menciona a Vizcaya. En segundo lugar, por su beligerancia. Y, last but not least, porque está escrito en castellano. Frente al poema de Arrieta-Mascarúa, Iparraguirre compone un himno de paz, dedicado al conjunto de Vasconia (o, al menos, a su parte peninsular), y en vascuence. De no ser por el fuerismo y por la motivación religiosa, presentes en ambos, casi podríamos afirmar que Iparraguirre se encuentra en las antípodas de Arrieta-Mascarúa. El poema de este ha sido olvidado casi por completo. No merece otra cosa. El Gernikako Arbola, en cambio, poseía todos los ingredientes para convertirse en el himno nacional vasco,

\footnotetext{
75 Arrieta Mascarúa, 1882 [escrito en 1840], p. 61.

76 Según Lasala (1924, I, p. 327), Egaña desconocía la lengua vasca, lo que podría explicar todo el embrollo.
} 
si, paradójicamente, no se hubiera interpuesto en su camino el fundador del nacionalismo político.

\section{El Gernikako Arbola y el nacionalismo vasco}

Sabino Arana (1865-1903) no tenía en gran estima el Gernikako Arbola. Su nacionalismo obtuso no congeniaba con el universalismo que rezuma el himno. Le resultaban especialmente repulsivos los versos quinto y sexto de la primera estrofa («Eman ta zabaltzazu/ Munduban frutuba», «da y expande tu fruto por el mundo»), contra los que se despachó a gusto en un artículo escrito en 1901, pero aparecido en la revista Euzkadi varios años después de su muerte:

Iparraguirre [...] interpretó fielmente la frivolidad, el craso error de los vascos de su tiempo. Quería que el roble extendiera su fruto allende el Ebro, cuando no lo daba ni para su país. Meternos a consejeros del hogar ajeno, cuando no sabemos gobernar el nuestro, es sencillamente ridículo. Dejar de atender a nuestra vida por hacer al extraño favores que, por inconvenientes, no quiere recibir, es criminal.

Dejémonos de poesías: palpemos la realidad y aprendamos a conocernos. Es muy bonito pedir que la justicia que simboliza el Arbol de Gernika la difunda por el mundo. Pero lo práctico es procurar fructifique de nuevo para el pueblo donde nació y vivió. Amemos a todos los hombres, amemos a todas las naciones; pero apliquémonos primero al bien de la nuestra. ¿Podríamos jamás hacerlo perfecto?

El Arbol de Gernika es símbolo del bienestar de nuestro pueblo: no de ningún otro. Ni dentro de nuestro solar puede coexistir con ningún otro Arbol. Estúpida fué la idea que sostuvieron los vascos en todo el siglo pasado de hacer compatibles las instituciones patrias con un poder extraño. Reconozcamos su yerro.

El Arbol de Gernika, cantado por Iparraguirre, no es símbolo de libertades vascas, sino de una paz universal, la cual sólo en la Cruz tiene su emblema. Pretender que las instituciones vascas se extiendan a todo el mundo... ¡insigne necedad!

Pero los vascos se pagan de apariencias: es letra euzkérica la de Iparragirre y al Arbol de nuestra independencia canta y esto les basta.

Hace ya un lustro se dijo que es antipatriótica la letra del Gernika. Poco después un periódico socialista la hizo suya, con mucha razón. En el discurso de los Juegos Florales se ha exhibido asimilada, con mucha lógica, a ideas refractarias al bien de los vascos. 

canta:

Pero los vascos siguen cantando la letra de Iparraguirre y nadie

emak da zabaltzazu

geurian frutuba

(da y propaga tu fruto en nuestra tierra) ${ }^{77}$.

No solo eso. El vascuence de Iparraguirre está plagado de castellanismos. Sabino, por el contrario, quería un euskara «puro». Hacia 1888 «tradujo» la primera estrofa del Gernikako Arbola a su propio idiolecto:

\author{
Luno'ko [sic] zugatz donia \\ Zeu zara onesana \\ Euskeldunen artian \\ Ta guztiz maitia \\ Geure errija estaleizu \\ Zeure zunbilagaz; \\ Lagijaizango-zara, \\ Beti, ... ${ }^{78}$.
}

En la versión de Sabino, el Roble ya no está en Gernika, sino en Lumo. Efectivamente, desde un estricto punto de vista histórico, las juntas vizcainas se reunían en la jurisdicción de la anteiglesia de Lumo, no en la de Gernika, que, además, era una mera villa. Según Sabino Arana, para quien la historia se había detenido con la abolición foral de 1876, las anteiglesias, donde regía el Fuero de Vizcaya, poseían un estatus superior al de las villas, creaciones de los señores y vehículos de castellanización.

Más radical fue incluso Luis Arana (1862-1951), el hermano mayor de Sabino, al que este atribuyó la concepción de la idea nacionalista. Como es sabido, la legión Cóndor y la aviación legionaria italiana bombardearon Gernika (y Lumo) el 26 de abril de 1937. En una carta fechada tan solo dos días más tarde, Luis se mostraba indignado por la atribución

77 Arana Goiri, 1915 [escrito en 1901]. La traducción de los versos finales es del propio Sabino Arana.

78 «Árbol santo de Luno/ Eres bendito/ Entre los Vascos/ Y muy amado/ Protege nuestro país/ Con tu tronco/ Serás la Ley/ Siempre, ...». Arana Goiri, 1991 [escrito hacia 1888], p. 272. La traducción es mía. 
del Roble a Gernika en lugar de a Lumo. Denunciar ese error le parecía bastante más imperioso que condenar la desolación provocada por nazis y fascistas:

\begin{abstract}
¿No debe saber todo nacionalista bizkaino por la historia de Bizkaya que el Arbol de Gernika símbolo de la libertad de Bizkaya se halla enclavado en la anteiglesia de Luno? [...] el que perpetró el atentado a la constitución bizkaina con la anexión más que fusión de la anteiglesia de Luno a la Villa de Gernika tomando corrientemente esta última denominación a pesar de su categoría bizkaina inferior a la de anteiglesia, fue Angel Allende Salazar, ministro de Gobernación de Cánovas del Castillo ${ }^{79}$.
\end{abstract}

Aunque pueda resultar sorprendente desde la perspectiva actual, una de las razones que explica el rechazo del himno de Iparraguirre por parte de los hermanos Arana Goiri es que parece conceder preeminencia a la villa sobre la anteiglesia.

En general, hasta la Guerra Civil, el nacionalismo vasco mantuvo una actitud ambivalente respecto al Roble de Gernika y el himno de Iparraguirre. El sector más pactista (que se articularía en torno a Comunión y ANV) aceptaba el orden legal español, que reconocía autonomía administrativa y fiscal a cada una de las provincias vascas por medio del régimen de Convenio o Concierto. Al sector independentista, que sería conocido como Aberri, al que pertenecería José Arriandiaga «Joala» (1856-1923), le repugnaba cualquier concesión del Estado español. Para «Joala», el Roble y el himno se convertirían en símbolos de la opresión española, que había que destruir cuanto antes:

El árbol de Guernica es, pues, un baldón de ignominia para nosotros; no es el árbol de la libertad, sino el que con su sombra nos quitó la libertad.

De él no debieran quedar ni astillas, ni de la Casa de Juntas piedra sobre piedra ni papel en su archivo sin quemarse, ni hierba en todos sus alrededores.

79 Al Bizkai-Buru-Batzar por medio de su Presidente Don Juan de Axuriagera (Abando, 28 de Abril de 1937), en Sarrailh de Ihartza, 1979 [1963], pp. 391-393 (392-393). La villa incorporó la antigua anteiglesia en 1882, a propuesta de Ángel Allendesalazar, que no era ministro de Cánovas, como pretende Luis Arana, sino diputado liberal, miembro de una familia de potentados de Lumo, herederos del muy ilustre linaje de los Meceta. 
¡Árbol de Guernica, árbol criminal, asesino de Bizkaya, maldito seas! ${ }^{80}$.

Esa, obviamente, no fue la postura de todo el nacionalismo vasco. Luis de Eleizalde (1878-1923), que pertenecería al sector mayoritario, Comunión, respondió a «Joala» con contundencia:

ese artículo de usted no es nacionalista, ni autonomista, ni fuerista, ni nada que indique una idea positiva - aunque fuese errónea ó incompleta.- El artículo de usted es, sencillamente, iconoclasta, destructivo, negativo ${ }^{81}$.

Esa duplicidad se mantuvo, o incluso se agudizó, en el nuevo nacionalismo que surge en los años 60. Por ejemplo, Federico Krutwig (19211998), autor de Vasconia (1963), considerada como la Biblia de la primera ETA, denomina al Gernikako Arbola «himno nacional vasco» ${ }^{82}$. Junto a estas palabras de respeto por la tradición fuerista, se puede constatar en miembros de la denominada izquierda abertzale una repulsión absoluta hacia ella. En este poema, Mikel Antza, que llegó a ser el máximo dirigente de ETA, se recrea imaginando cómo destruye a hachazos el Árbol de Gernika:

Ni nintzen aizkolari, albokari, txistulari, Gernikako Arbola guztiz txikitzen $\operatorname{ari}^{83}$.

\section{El Gernikako Arbola y el navarrismo}

Ya se ha dicho que Iparraguirre compuso su himno al menos para las cuatro provincias vasco-españolas. Los primeros navarristas lo cantaron con bastante más fervor que los primeros bizkaitarras. En los sanfermines de 1894, coincidiendo con la Gamazada, la plaza de toros de Pamplona lo

\footnotetext{
80 Arriandiaga, 1909.

81 Eleizalde, 1909.

82 Sarrailh de Ihartza, 1979 [1963], p. 297.

83 Antza, 1986.
} 
coreaba al unísono ${ }^{84}$. En 1905, un artículo del ultraconservador Diario de Navarra daba noticia de la inauguración del Centro Navarro de San Sebastián y concluía:

Después del banquete se prolongó la reunión por buen espacio de tiempo cruzándose las más cordiales señales de estrecha unión entre guipuzcoanos y navarros cantándose varias veces el Guernikako Arbola en medio del mayor entusiasmo ${ }^{85}$.

El propio director del Diario, Raimundo García «Garcilaso» (18841962), tampoco escatimaba elogios para el Gernika en 1912:

Porque es verdad, y así hay obligación de proclamarlo, que entre los sentimientos que dan calor y vida en Cataluña y en Vasconia á las empresas reivindicadoras de los respectivos derechos, hay una distancia demasiado grande para que ambas cuestiones, la catalana y la foral, puedan ser tomadas por una misma cosa.

«Els Segadors», es un canto de odio, sanguinario, cruel. «El Guernikako», es un canto de amor, de respeto, generoso, bueno ${ }^{86}$.

No deja de ser curiosa la reivindicación del pacifismo del Gernikako Arbola frente al belicismo de Els Segadors por quien tuvo parte activa en la organización en Navarra del cruento golpe militar de 1936. Sea como fuere, «Garcilaso» y las elites navarras a las que representaba, que hoy son el bastión contra el nacionalismo vasco en el Viejo Reino, no veían ningún peligro en un himno fuerista que se limitaba a exaltar la identidad vasca sin negar la española.

Contra lo que pudiera pensarse, el Gernikako Arbola era conocido en toda Navarra, no solo en Pamplona y la zona vascófona. Tal fue su difusión en la Ribera que para acompañar al zorcico se redactaron múltiples versiones en castellano. Una de las más conocidas es la que los tudelanos cantaron en febrero de 1894 a los diputados forales que se dirigían en tren a Madrid con motivo del célebre artículo 17 del proyecto de la Ley de presupuestos del ministro de Hacienda, Germán Gamazo, considerado antiforal:

\footnotetext{
${ }^{84}$ Antoñana, 1999, p. 86.

85 Diario de Navarra, 1905.

${ }^{86}$ Garcilaso, 1912.
} 
Tudela te saluda

Diputación Foral

Y quiere que este canto

Te dignes escuchar.

Nuestras vidas y haciendas

Tuyas desde ahora son

Y nadie a nuestros Fueros

Vendrá a echar un borrón.

Porque aquí hay corazón

Do late el patrio amor

Y quieren más la muerte

Que vivir sin honor ${ }^{87}$.

Otra es la que cantaban los de Sesma y otros pueblos de la Ribera estellesa, unos días más tarde:

El árbol de Gernika

por siempre vivirá.

Si se secan sus ramas

del tronco brotará 88 .

En el segundo pueblo más meridional de Navarra, Monteagudo, por la misma época, la música del Guernicaco-arbolá [sic] acompañaba la representación de su precioso paloteado, con letra de José Jarauta «Joselico» (1857-1950), un labrador del vecino Tulebras ${ }^{89}$.

Pero todo eso es historia. La ideología mayoritaria en la llamada Comunidad Foral de Navarra, un navarrismo de nuevo cuño que ha abjurado de su originario fuerismo vasquista, ha condenado el Gernikako Arbola al ostracismo. En ocasiones, el PSOE ha resultado más papista que el papa y más navarrista que UPN. Por ejemplo, José Antonio Pérez Sola, alcalde socialista de Tudela, llegó a afirmar en 1988 que el Árbol de Gernika es un instrumento del imperialismo «vasco» que no tiene nada que ver con Navarra $^{90}$. Esta actitud del regidor tudelano contrasta con la de dos líderes históricos del navarrismo conservador, ambos presidentes del Gobierno de

87 En Ergabia 1932, p. 51.

88 En Antoñana, 1999, p. 86; cursivas suprimidas.

89 Jimeno Jurío, 1973.

90 Sanz de Ayala, 1988. 
Navarra, Jaime Ignacio del Burgo ${ }^{91}$ y Juan Cruz Alli ${ }^{92}$, que no tuvieron reparo en escribir sendas aportaciones para el libro de Gontzal Mendibil sobre Iparraguirre.

Eso por hablar del navarrismo «respetable». Porque unos fanáticos navarristas destrozaron un retoño del Árbol de Gernika en Estella en octubre de $2009^{93}$. Ironías de la vida: casi cumplieron el sueño de los fanáticos abertzales «Joala» y Mikel Antza.

\section{Conclusiones}

El fundador del nacionalismo político vasco, Sabino Arana, ya se ha dicho, no tenía un gran concepto de la composición de Iparraguirre, un «himno exclusivamente bizkaino» ${ }^{94}$, según sus palabras. Con la explícita intención de relegarlo, en 1902 Arana Goiri escribió la versión actual de la letra del Himno de la Raza Vasca o Gora ta Gora ${ }^{95}$, escogiendo como melodía nacional de Euzkadi la marcha Agintariena, que, curiosamente, pertenece al ciclo Dantzari-dantza del Duranguesado, el mismo que, según Arana Martija, inspiró a Iparraguirre (o a Altuna) ${ }^{96}$. Desde 1983, la música de ese himno, arreglada por Cleto Zabala, no así la letra, en euskara, de Arana Goiri (que también alude al Roble de Gernika), es, pese a su escaso arraigo popular, oficial en la Comunidad Autónoma del País Vasco, la entidad que engloba a tres de los cuatro territorios para los que se compuso el Gernikako Arbola ${ }^{97}$. En el cuarto de ellos, Navarra, se declaró en 1986 la oficialidad del Himno de las Cortes, una marcha del siglo XVIII de origen ignoto y autoría anónima, que, junto con una letra (escrita en castellano por Manuel Iribarren y traducida al vascuence por José María Azpíroz), añadida en 1971 por iniciativa de la Diputación Foral,

91 Del Burgo, 1999.

92 Alli, 1999.

93 Diario Vasco, 2009.

${ }_{94}$ Basoa (que si no es el propio Sabino Arana es alguien muy cercano a él), 1897; cursivas en el original.

95 Arana Goiri, 1980 [1902]. Como en la oda de Arrieta-Mascárua, Vizcaya es la única provincia mencionada en el himno de Sabino. La diferencia es que este está dedicado a Euzkadi, un concepto, el de la unidad política vasca, inexistente en 1840.

96 Véase nota 37 y Larrinaga, 2008.

${ }^{97}$ El Gora ta Gora también fue oficial en 1936-1937, con el primer Gobierno Vasco. Arrieta Alberdi, 2013. 
ha sido aceptada por la población sin polémicas, pero también sin entusiasmo ${ }^{98}$. Con la polarización política que siguió a la muerte de Franco y el establecimiento del Estado de las Autonomías, el fuerismo panvasquista y, a la vez, españolista del bardo guipuzcoano resultó obsoleto. El Gernikako Arbola, que hasta entonces había sido cantado en las cuatro provincias vasco-españolas por gentes muy diversas, quedó huérfano: ninguna de las dos nuevas comunidades autónomas en las que quedó estructurada la Euscal erria de Iparraguirre ni de las ideologías antagónicas que se convirtieron en mayoritarias en cada una de ellas (nacionalismo antiespañol y navarrismo antivasco, gemelos siameses surgidos del fuerismo) le reconocieron el rango de «himno nacional», que durante tanto tiempo había desempeñado de manera oficiosa. La otra cara de la moneda es que, a pesar de no haber sido pensado en un principio para ellos, en los tres territorios de la Vasconia francesa, que ni siquiera existen legalmente desde la Revolución, sigue siendo muy popular, al menos entre la gente de cierta edad ${ }^{99}$. Todo ello por no hablar de la Diáspora vasca, donde el canto de Iparraguirre es mucho más conocido que los himnos oficiales de Euskadi y de Navarra. A pesar de su «orfandad», institucional y territorial, o, tal vez, precisamente a causa de ella, bastante más de siglo y medio después del recital del Café San Luis, el Gernikako Arbola sigue siendo capaz de unir y emocionar a los vascos por encima de fronteras y divisiones administrativas.

\section{Bibliografía}

Agud, Manuel y Tovar, Antonio, «Aritz», en Diccionario etimológico vasco, Diputación Foral de Guipúzcoa, Anejos del Anuario del Seminario de Filología Vasca «Julio de Urquijo», San Sebastián, XIX, II, 1990, pp. 11-12.

AlLI, Juan Cruz, «Eman da zabal zazu munduan frutuba (Esparce tu fruto por el mundo)», en MENDIBIL, Gontzal (dir.), Jose Maria Iparragirre. Erro-urratsak. Raíz y viento, Keinu, Igorre (Bizkaia), 1999, II, pp. 75-82.

98 Huici Goñi et al., 1987.

99 Según Krutwig, «Todavía hoy en día [1963] en la población rural es excepción los euskaldunes que conocen la Marsallesa [sic], mientras que casi todos conocen texto y música del Gernikako Arbola» (Sarrailh de Ihartza, 1979 [1963], p. 297). El bajonavarro Jean Haritschelhar (1923-2013), que llegó a ser presidente de la Academia de la Lengua Vasca, recuerda que, siendo niño, en la escuela de su localidad natal de Baigorri, los alumnos lo cantaban junto con La Marsellesa. En Arana Martija, 1999, p. 112. 
Álvarez GILA, Óscar, «La emigración vasca al Río de la Plata en el siglo XIX (La América que encontró Iparraguirre)», en MENDIBIL, Gontzal (dir.), Jose Maria Iparragirre. Erro-urratsak. Raíz y viento, Keinu, Igorre (Bizkaia), 1999, II, pp. 137-148.

AntoñanA, Pablo, «Iparragirre y los míos», en MendibIL, Gontzal (dir.), Jose Maria Iparragirre. Erro-urratsak. Raíz y viento, Keinu, Igorre (Bizkaia), 1999, II, pp. 83-86.

AnTZA, Mikel (=Albisu IrIARTE, Mikel), «Aizkolari». El poema aparece como letra de una canción del grupo de rock radical vasco Kortatu, que forma parte de su disco El estado de las cosas (1986).

ArAnA GoIRI, Sabino de, «Gernikako arbola» [escrito hacia 1888], en CORCUERA, Javier, et al. (ed.), Historia del nacionalismo vasco en sus documentos. Iconografía nacionalista, Eguzki, Bilbao, 1991, IV, pp. 271-272.

[Arana GoIrI, Sabino de], «Remedio ineludible», Bizkaitarra, 14 de septiembre de 1893.

[Arana GoIRI, Sabino de], «Gipuzkoa», Bizkaitarra, 10 de diciembre de 1893.

[ArANA GoIRI, Sabino de], «iViva Nabarra!», Bizkaitarra, 19 de febrero de 1894.

ArAnA GoIRI, Sabino de, «Conócete a ti mismo» [escrito en 1901], Euzkadi. Revista Trimestral de Ciencias, Bellas Artes y Letras, 7 de enero de 1915.

ArANA GoIRI, Sabino de, «Euzko-Abendearen Ereserrkija» [1902], en Obras completas, Sendoa, San Sebastián, 1980, III, p. 2413.

Arana MARTIJA, José Antonio, «Iparragirre eta Bizkaia», en EUSKALTZAINDIA, Iparragirre, Euskaltzaindia, Bilbao, 1987, pp. 283-299.

Arana Martija, José Antonio, «Gernikako Arbola», en MendibiL, Gontzal (dir.), Jose Maria Iparragirre. Erro-urratsak. Raíz y viento, Keinu, Igorre (Bizkaia), 1999, II, pp. 105-116.

ArriandiagA, José de, «El árbol de Guernica», El Nervión, 2 de marzo de 1909.

ArRIETA Alberdi, Leyre, «¿Cuál es el himno de los vascos? El nacionalismo vasco y su simbología musical», Spagna Contemporanea, 44, 2013, pp. 7-27.

Arrieta Mascarúa, José M. de, «El árbol de Guernica» [escrito en 1840], Revista Euskara, V, 1882, pp. 58-61.

Arrillaga Arriola, Antonio (ed.), Lo que se ha dicho de Iparraguirre, autor del himno Guernikako Arbola, Junta de Cultura de Vizcaya, Bilbao, 1967 (2) [1953].

BARANDIARÁN, José Miguel de, «Arixo», en Diccionario ilustrado de mitología vasca y algunas de sus fuentes, La Gran Enciclopedia Vasca, Bilbao, 1972, p. 32.

BASOA (= ¿ARANA GoIRI, Sabino?), «Pifias del Orfeón Pamplonés y nueva profanación del "Gernika"», Baserritarra, 13 de junio de 1897.

BECERRO DE BENGOA, Ricardo, «La vuelta de Iparraguirre» [1879], en ARRILlaGA ARriola, Antonio (ed.), Lo que se ha dicho de Iparraguirre, autor del himno Guernikako Arbola, Junta de Cultura de Vizcaya, Bilbao, 1967 (2) [1953], pp. 133-140. 
Bernadou, Charles, Azpeitia. Les fêtes euskariennes au pays de saint Ignace. Septembre 1893, Imprimerie A. Lamaignère, Bayonne, 1894.

CARo Baroja, Julio, Ritos y mitos equívocos, Istmo, Madrid, 1989 [1974].

CASTRESANA, Luis de, Vida y obra de Iparraguirre. Seguida de la obra completa (original euskera y versión castellana) del autor del Gernika'ko Arbola, La Gran Enciclopedia Vasca, Bilbao, 1971.

CÉnAC-Moncaut, M., Histoire des Pyrénées et des rapports internationaux de la France avec l'Espagne depuis les temps les plus reculés jusqu'à nos tours, Amyot, Paris, V, 1855.

CHAно, J. Augustin, Voyage en Navarre pendant l'insurrection des Basques (18301835), P. Lespés Éditeur, Bayonne, 1865 (2) [1836].

Chано, Augustin, «Aïtor. Légende cantabre», Ariel. Courier des Pyrénées, Journal International, Scientifique, Artistique et Littéraire, 8 de junio de 1845.

Снано, Augustin, Biarritz, entre les Pyrénées et l'Océan. Itinéraire pittoresque, A. Andreossy, Bayonne, 1855, 2 tomos.

Del Burgo, Jaime Ignacio, «Iparraguirre, el bardo de los Fueros», en MENDIBIL, Gontzal (dir.), Jose Maria Iparragirre. Erro-urratsak. Raíz y viento, Keinu, Igorre (Bizkaia), 1999, II, pp. 121-128.

De Pablo, Santiago, «Roble», en DE PABLO, Santiago, et al., Diccionario de símbolos del nacionalismo vasco, Tecnos, Madrid, 2012, pp. 648-663.

DiARIO DE NAVARRA, «El centro navarro de San Sebastián», Diario de Navarra, 3 de enero de 1905.

DiARIO VASCO, «Talan a hachazos un retoño del árbol de Gernika en Estella», Diario Vasco, 7 de octubre de 2009.

[EgAÑA, Pedro de], «Bardo vascongado», La España, 13 de junio de 1855.

EGAÑA, Pedro de, «Iparraguirre en la defensa de los fueros» [1864], en ARRILlAGA ARriola, Antonio (ed.), Lo que se ha dicho de Iparraguirre, autor del himno Guernikako Arbola, Junta de Cultura de Vizcaya, Bilbao, 1967 (2) [1953], pp. 243-247.

ElEIZALDE, Luis de, «El Árbol de Guernica», Bizkaitarra, 6 de marzo de 1909.

Elías de Tejada, Francisco, El Señorío de Vizcaya (Hasta 1812), Minotauro, Madrid, 1963.

EnsunZa ARrien, Maider, Gernika: estudio histórico-artístico, Diputación Foral de Bizkaia, Bilbao, 2003.

ERgABIA, Miguel de (=SALAMERO RESA, Juan José), La Erribera por JEL. Folleto de propaganda nacionalista, Talleres de Euzkadi, Bilbao, 1932.

ESTORNÉs ZuBIZARRETA, Idoia, «Árbol», en Enciclopedia General Ilustrada del País Vasco, Auñamendi, San Sebastián, II, 1976, pp. 289-294.

EusKALTZAINDIA, Iparragirre, Euskaltzaindia, Bilbao, 1987.

EzKERRO, Mikel, «José María Iparragirre en Argentina», en MENDIBIL, Gontzal (dir.), Jose Maria Iparragirre. Erro-urratsak. Raíz y viento, Keinu, Igorre (Bizkaia), 1999, II, pp. 149-160. 
FRAZER, James George, La rama dorada. Magia y religión, Fondo de Cultura Económica, México, Madrid, Buenos Aires, 1951 [1890].

GÁrate, Justo, «XIII contribución al Diccionario Vasco», Fontes Linguae Vasconum, 5, 15, 1973, pp. 329-332.

GÁRATE ARRIOLA, Justo, «Iparraguirre en América», en EUSKALTZAINDIA, Iparragirre, Euskaltzaindia, Bilbao, 1987, pp. 161-265.

García Quintela, Marco V., y DelPech, François, El Árbol de Guernica. Memoria indoeuropea de los ritos vascos de soberanía, Abada Editores, Madrid, 2013.

García de Cortázar, José Ángel, et al., Bizcaya en la Edad Media, Haranburu Editor, San Sebastián, 1985, 4 tomos.

GARCILASO (=GARcía GARcíA, Raimundo), «Literatura vasca. Ideas de nuestro tiempo. Adrián de Loyarte», Diario de Navarra, 25 de septiembre de 1912.

Grandmontagne, Francisco, «Una entrevista con Ángela Querejeta» [1897], en MENDIBIL, Gontzal (dir.), Jose Maria Iparragirre. Erro-urratsak. Raíz y viento, Keinu, Igorre (Bizkaia), 1999, II, pp. 173-182.

GuERrA, Juan Carlos de, Estudios de heráldica vasca, Librería Internacional, San Sebastián, 1927 (3).

GuEzala, Luis de, Las instituciones de Bizkaia a finales del Antiguo Régimen (1793-1804), Bilbao Bizkaia Kutxa, Bilbao, 1992.

HARITSCHELHAR, Jean, «Gernikako Arbola véritable hymne basque», Lapurdum, V, $2000<$ http://lapurdum.revues.org/1332> [consultado 19/11/2016].

Huici GoÑI, María Puy, et al., El himno de Navarra: «Marcha para la entrada del Reyno», Gobierno de Navarra, Pamplona, 1987.

IPARRAGUIRRE, José María, «Guernicaco arbola» [1853], en SANTESTEBAN, J.A., Colección de aires vascongados para canto y piano, Almacén de Música, San Sebastián, 1862, n. ${ }^{\circ} 2$.

IPARRAGUIRRE, José María, «Nere etorrera lur maitera» [1877], en MENDIBIL, Gontzal (dir.), Jose Maria Iparragirre. Erro-urratsak. Raíz y viento, Keinu, Igorre (Bizkaia), 1999, I, p. 306.

Jimeno JuRío, José María, «Paloteado de Monteagudo», Cuadernos de Etnología y Etnografía de Navarra, V, 15, 1973, pp. 259-300.

LABAYEN, Antonio M. ${ }^{\text {, }, ~ « I p a r r a g u i r r e: ~ t e m a ~ c o n ~ v a r i a c i o n e s », ~ B o l e t i ́ n ~ d e ~ l a ~ R e a l ~}$ Sociedad Bascongada de Amigos del País, XXVIII, 1972, pp. 362-377.

LABORDA, Juan José, El Señorío de Vizcaya. Nobles y fueros (c.1452-1727), Marcial Pons, Madrid, 2012.

LARRINAGA, Josu, «Dantzari-dantza», en Auñamendi Eusko Entziklopedia, $2008<$ http:// www.euskomedia.org/aunamendi/ee150093?idi=es $>$ [consultado 19/11/2016].

LASAla y COLLADO, Fermín de, Última etapa de la unidad nacional. Los fueros vascongados en 1876, Real Academia de Ciencias Morales y Políticas, Madrid, 1924, 2 tomos.

LinaZASORo, Iñaki, José María Iparraguirre, Caja de Ahorros Provincial de Guipúzcoa, San Sebastián, 1977. 
LIRIS, E., «Arbres de la liberté», en SOBOUL, Albert, Dictionnaire historique de la Révolution Française, Presses Universitaires de France, Paris, 1989, p. 30.

Luengo Teixidor, Félix, y Delgado Cendagortagalarza, Ander, «El árbol de Gernika. Vicisitudes del símbolo foral de los vascos», Historia y Política, 15, 2006, pp. 23-44.

LukKen, G.M., Original Sin in the Roman Liturgy, E.J. Brill, Leiden (Netherlands), 1973.

MAdARIAGa ORBEA, Juan, «Estatuto social y representación política», Iura Vasconiae, 3, 2006, pp. 317-364.

Manterola, José, Cancionero vasco. Poesías en lengua euskara reunidas en colección, ordenadas en series, y acompañadas de traducciones castellanas, juicios críticos, noticias biográficas de los diversos autores, y observaciones filológicas y gramaticales, Imprenta de Juan Osés, San Sebastián, I (1877) y III (1878).

MaÑé Y Flaquer, Juan, El oasis: viaje al país de los Fueros, Imprenta de Jaime Jepús Roviralta, Barcelona, II, 1879.

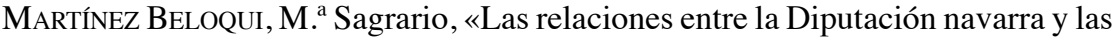
Provincias Vascongadas en 1866», en Noveno Congreso de Estudios Vascos (1983), Eusko Ikaskuntza, Bilbao, 1984, pp. 463-465.

MeNDIBIL, Gontzal (dir.), Jose Maria Iparragirre. Erro-urratsak. Raíz y viento, Keinu, Igorre (Bizkaia), 1999, 2 tomos.

Michel, Francisque, Le Pays Basque, sa population, sa langue, ses moeurs, sa littérature et sa musique, Librairie de Firmin Didot Frères, Fils et Cie, Paris, Londres et Edinbourg, 1857.

MoLINA, Tirso de, «La prudencia en la mujer» [1634], en La prudencia en la mujer. El condenado por desconfiado, Tiempo, [s.1.], 2004, pp. 5-126.

Monreal Cía, Gregorio, Las instituciones públicas del Señorío de Vizcaya (hasta el siglo XVIII), Diputación de Vizcaya, Bilbao, 1974.

Olascoaga, F. de, «Otros árboles históricos», Boletín de la Comisión de Monumentos de Vizcaya, I, 3, 1909, pp. 52-60.

Olaso, José Francisco, y AGUIRRE, Juan, «Iparragirre: izena eta izana. Retrato sin retoques», en MENDIBIL, Gontzal (dir.), Jose Maria Iparragirre. Errourratsak. Raiz y viento, Keinu, Igorre (Bizkaia), 1999, I, pp. 29-180.

Ordenación, descripción e indización del fondo de la Capitanía General de Vascongadas del Archivo General Militar de Madrid, Archivo General Militar de Madrid, Madrid, 2004.

PeÑa GoÑI, Antonio, «Iparraguirre. Discurso del Sr. D. Antonio Peña y Goñi, leído por su autor en el solemne acto de la inauguración de la Estatua de Iparraguirre, el 28 de Setiembre de 1890», Euskal-Erria, XXIII, 368, 1890, pp. 257-266.

Pouvreau, Silvain, Dictionnaire Basque-Français, manuscrito, datado hacia 1665 .

Rubio Pobes, Coro, La identidad vasca en el siglo XIX. Discurso y agentes sociales, Biblioteca Nueva, Madrid, 2002. 
SÁnchez EkiZA, Karlos, «Sobre Iparraguirre y el Gernikako arbola», Musiker. Cuadernos de Música, 15, 2007, pp. 151-163.

SANTESTEBAn, J.A., Colección de aires vascongados para canto y piano, Almacén de Música, San Sebastián, 1862.

SANZ DE AYALA, Juan Carlos, «La sombra invasora del Árbol de Guernica. Tudela rechaza un retoño enviado desde Vizcaya», Época, 190, 24-30 octubre 1988, pp. 72-74.

Sarrailh de Ihartza, Fernando (=Krutwig Sagredo, Federico), La nueva Vasconia, Ediciones Vascas, San Sebastián, 1979 [1963].

Soraluce Zubizarreta, Nicolás de, Gloria y gratitud al inmortal autor de Primus me circumdedisti Juan Sebastián del Cano, Imprenta de Domingo Sar, Vitoria, 1882.

TILlyard, Eustace Mandeville Wetenhall, The Elizabethan World Picture, Transaction Publishers, New Brunswick, London, 2011 [1959].

VÁZQUEZ DE PRADA, Mercedes, Negociaciones sobre los fueros entre Vizcaya y el poder central (1839-1877), Caja de Ahorros Vizcaína, Bilbao, 1984.

Vovelle, Michel, «La Marseillaise. La guerre ou la paix», en NORA, Pierre (dir.), Les lieux de mémoire, Gallimard, Paris, 1997 [1984-1992], I, pp. 107-152.

WORDSWORTH, William, «The Oak of Gernika» [escrito en 1810, publicado en 1815], en Zoellner, Renate (ed.), William Wordsworth, Politician and Poet. The Spanish and Basque Sonnets and Their Background, Enseiucarrean, Bilbao, 1988, sin paginar.

ZabaltZA, Xabier, Mater Vasconia. Lenguas, fueros y discursos nacionales en los países vascos, Hiria, San Sebastián, 2005.

\section{Financiación}

Gobierno Vasco. Grupo de investigación del sistema universitario vasco. IT658-13.

\section{Datos del autor}

Xabier Zabaltza-Pérez-Nievas (xabier.zabaltza@ehu.eus) es profesor de Historia Contemporánea de la Universidad del País Vasco. Su obra académica incluye los libros Mater Vasconia. Lenguas, fueros y discursos nacionales en los países vascos (2005) y Una historia de las lenguas y los nacionalismos (2006 y 2010). En su ensayo Gu, nafarrok (2007), que apareció en castellano con el título de Nosotros, los navarros (2009), abordó de manera crítica las identidades contrapuestas de Navarra. Es, además, autor de una biografía en euskara del escritor suletino Augustin Chaho (Aitzindari bakartia, 2011), editada también en castellano y en francés, y, con Iván Igartua, de una Breve historia de la lengua vasca (2012 y 2016), en castellano, vascuence, inglés y francés. 